\title{
Running-related demands and vigor in long-distance runners: The moderating role of resources and recovery
}

\author{
Luuk P. van Iperen ${ }^{1}$ (D) J Jan de Jonge ${ }^{1,2,3} \cdot$ Josette M. P. Gevers ${ }^{1} \cdot$ Steven B. Vos ${ }^{4,5}$ \\ Published online: 8 July 2020 \\ (C) The Author(s) 2020
}

\begin{abstract}
Long-distance running is a demanding sport and runners use a variety of coping strategies to deal with these demands. In this study, we investigated running-related demands, resources, and recovery and, as an indicator of well-being, vigor. Specifically, following the Demand-Induced Strain Compensation Recovery Model, we tested to what degree the relation between runningrelated demands and vigor was moderated by two coping strategies available in running: running-related resources (e.g., training control, running mate/coach support) and running-related recovery (i.e., detachment from running). Demands, resources, recovery, and vigor were all surveyed across three separate dimensions (i.e., physical, cognitive, emotional) in a cross-sectional sample of 623 recreational long-distance runners. Hierarchical regression analyses were used to determine to what degree the demandsvigor relation was moderated by resources and recovery. Evidence for moderations was found for the cognitive and emotional dimensions of vigor, revealing four significant moderating effects of resources or recovery on the demands-vigor relation. Three of these effects involved emotional resources or recovery. Contrary to expectations, results also showed that in two cases higher recovery was associated with lower vigor, rather than higher, when runners experienced high demands. In all, we found modest support for the role of resources and recovery in altering the nature of the demands-vigor relation in recreational long-distance runners. This study highlights the importance of the emotional dimension of demands, resources, and recovery, as those facets were most important in predicting vigor in runners. Practical implications are addressed with regard to emotional resources and recovery for long-distance runners.
\end{abstract}

Keywords Detachment $\cdot$ Vigor $\cdot$ Emotion $\cdot$ Long-distance running $\cdot$ DISC-R model

\section{Introduction}

\section{Background}

Recreational running is one of the most popular contemporary sports across the globe (Hulteen et al. 2017; Scheerder et al.

Luuk P. van Iperen

1.p.v.iperen@tue.nl

Jan de Jonge

j.d.jonge@tue.nl

Josette M. P. Gevers

j.m.p.gevers@tue.nl

Steven B. Vos

s.vos@tue.nl

1 Human Performance Management Group, Department of Industrial Engineering and Innovation Sciences, Eindhoven University of Technology, P.O. Box 513, 5600 MB Eindhoven, The Netherlands
2015). It brings about many positive effects (Shipway and Holloway 2013; Walter et al. 2013), including higher wellbeing (Grunseit et al. 2017; Nezlek et al. 2018; Evans et al. 2017), lower mortality risk (Lee et al. 2014; Pedisic et al. 2019), and higher life satisfaction (Sato et al. 2015). However, increasing efforts in one's running, such as running

2 Department of Social, Health and Organisational Psychology, University of Utrecht, P.O. Box 80140, 3508

TC Utrecht, The Netherlands

3 School of Psychology, Asia Pacific Centre for Work Health and Safety, University of South Australia, P.O. Box 2471, Adelaide, SA 5001, Australia

4 Department of Industrial Design, Eindhoven University of Technology, P.O. Box 513, 5600 MB Eindhoven, The Netherlands

5 School of Sport Studies, Fontys University of Applied Sciences, P.O. Box 347, 5600 AH Eindhoven, The Netherlands 
faster or further, may not automatically relate to higher wellbeing and health (Pedisic et al. 2019). Running has also been associated with negative outcomes, such as injuries and exercise addiction (e.g., Landolfi 2012; van Poppel et al. 2018). The possibility of positive and negative outcomes of running partially depends on unique individual characteristics, such as running motivation (Shipway and Holloway 2013). In addition to these characteristics, we propose in this paper that certain running-specific conditions are related to well-being and health outcomes, too.

As self-imposed running efforts may induce both risks and rewards, runners are required to carefully balance these efforts with adequate coping strategies (e.g., resources and recovery) to achieve optimal well-being and health. This is particularly true for long-distance runners (i.e., those training for half marathons and more), given their higher training time and volume compared to their shorter-distance counterparts (van Poppel et al. 2018). Hence, a better understanding of the employment of coping strategies in the relation between running-related efforts and runners' well-being and health can unlock potential for training optimization. This is especially important in case of well-being outcomes, such as happiness and satisfaction, as these may relate to long-term sport adherence with its associated benefits (Stenseng et al. 2015). A better understanding of effectiveness of these coping strategies could be used to encourage lifelong and sustainable sport participation. Accordingly, the key question of this article concerns how recreational long-distance runners can optimize their running efforts by employing specific coping strategies to maintain or even improve their well-being.

\section{Running-Related Demands, Resources, and Recovery}

Investigating the relation between running efforts and wellbeing requires a further specification of those efforts. Longdistance runners face a variety of so-called running-related demands in their sport; that is, aspects of running which require immediate or sustained effort (de Jonge and Dormann 2017; de Jonge et al. 2018). Runners are exposed not only to physical demands (e.g., the bodily exertion of training), but also to cognitive and emotional demands (Balk et al. 2018a; Heidari et al. 2018). Cognitive demands are efforts that impinge primarily on information processing and complex decision-making, and refer to focus, concentration, precision and tactics. For instance, long-distance runners must often run precisely, focused and concentrated. During competition, runners need to retrieve previously stored information about tactics, pacing, and opponents. Emotional demands are concerned with running-related efforts such as dealing with disappointments, conflicts, or negative social experiences. For example, a runner may have to deal with cancelling a race due to injuries or may be very disappointed about his or her training progress.
To deal with these demands, runners can utilize a variety of coping strategies. A first coping strategy concerns situational running-related resources, which are defined as coping assets available in the running environment that can help to deal with demands. Running-related resources also consist of primarily physical, cognitive, and emotional components (Balk 2018). Examples include the ability to take a breather during training (physical), having control over training tasks (cognitive), and receiving empathy and help from a running coach (emotional).

A second coping strategy is running-related recovery. Recovery can generally be defined as a dynamic process of restoration (Kellmann et al. 2018) and unwinding in which a person's functioning and efforts return to their initial levels before the efforts took place. Recovery (i.c., from running) usually takes place away from the training environment (Balk and Englert 2020). From a physical perspective, recovery reduces and prevents the accumulation of physical fatigue that leads to poor health. From a psychological perspective, it allows the individual to prepare for current or new efforts. Like demands and resources, recovery can be divided in physical (e.g., no longer feeling the fatigue resulting from the physical exertion), cognitive (e.g., not thinking about running after ones' training), and emotional (e.g., emotionally distancing oneself from experiences during running) dimensions. All these dimensions of recovery are considered an integral part of running training and vital in preserving runners' well-being and health (de Jonge et al. 2018). In summary, considering the physical, cognitive and emotional demands placed on longdistance runners, the role of coping strategies (i.e., resources and recovery) in running therefore seems important in promoting runners' well-being and health.

\section{The Demand-Induced Strain Compensation Recovery Model}

Several theoretical frameworks have been developed to explain the role of resources and recovery in the relation between sport-related demands and athlete outcomes such as wellbeing and health (Balk 2018). One of such frameworks is the Demand-Induced Strain Compensation Recovery (DISCR) Model (cf. de Jonge et al. 2012; Balk 2018). The DISC-R Model, as depicted in Fig. 1, proposes that demands lead to certain outcomes and, more importantly, that this relation is moderated by the resources and recovery that one may employ. More specifically, it predicts that optimal outcomes

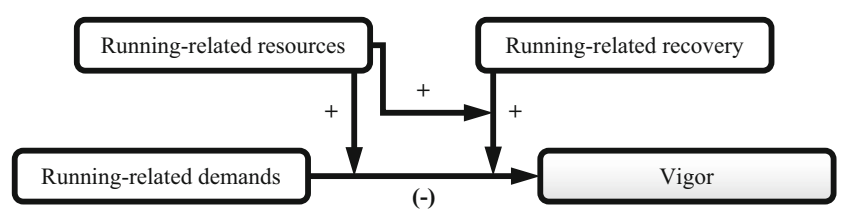

Fig. 1 Research model 
occur when high demands are coupled with high resources (i.e., activation-enhancing mechanism; see Balk 2018) or high recovery (i.e., preventing underrecovery, see Kellmann et al. 2018). Moreover, runners experiencing high demands can utilize both high resources and high recovery, implying that the corresponding moderating effect is expected to be stronger than either resources or recovery individually. In other words, we expect these constructs to provide unique and cumulative value in optimizing the demands-outcomes relation.

The effectiveness of the proposed moderations in the DISC-R Model is assumed to depend on their dimensions, an idea coined the 'match principle' (de Jonge and Dormann 2006). This idea of 'match' proposes that the most effective employment of resources and/or recovery occurs when these constructs align on the same dimension (i.e., physical, cognitive, and emotional) as demands and outcomes (Balk et al. 2020). To illustrate, imagine a runner who is having a negative social interaction with his trainer (i.e., emotional demand) which is negatively affecting his mood (i.e., emotional wellbeing outcome). Emotional support from teammates (i.e., an emotional resource) is more likely to be of value in this situation than instructions on running technique (i.e., cognitive resource). In a different fashion, a runner undergoing a physically straining training (i.e., physical demand) may over time gain physical fitness (i.e., physical well-being outcome). The resulting gains are likely to be even stronger when the runner can take a nap after long training sessions (i.e., physical recovery), compared to when he receives a compliment about his training from a fellow runner (i.e., emotional resource). This idea of match suggests that all relations between predictors (i.e., demands, resources, and recovery) and outcome (i.e., well-being) are stronger if they match on an identical dimension (i.e., physical, cognitive, emotional). In the context of sport, partial evidence for these matching mechanisms has been established separately for demands and resources (Balk et al. 2020) as well and demands and recovery (Balk et al. 2017), yet never in unison.

Furthermore, there are several types of 'match'. A combination of demands, resources, and outcomes all matching on one dimension (e.g., emotional) is an example of a 'triple match'. When demands and resources are of the same dimension, but the outcome is of a different dimension, we refer to it as 'double match'. Variants of a triple match exist (e.g., replacing resources with recovery), as do variants of 'double matches' (e.g., with demands and outcomes on the same, but recovery on a different dimension). Double matches are expected to be weaker than triple matches, but still stronger than a 'non-match' which is defined as the absence of any match between demands, resources, recovery, and/or outcome. These predictions imply that demands are most effectively moderated by matching (i.e., of the same dimension) resources or recovery, which is then expected to result in better well-being outcomes. Accordingly, the DISC-R Model predicts that the strength of moderating effects between demands, resources and recovery in the prediction of well-being increases as the degree of match increases (i.e., from nonmatch, via double-match, to triple-match; Balk et al. 2017).

\section{Vigor}

As a key indicator of well-being of long-distance runners, we selected vigor as our outcome measure. Shirom $(2003,2011)$ defines vigor as a moderate-intensity affect consisting of three dimensions: physical strength, cognitive liveliness, and emotional energy. Other definitions of vigor in the scientific literature focus on vitality (Hausswirth and Mujika 2013) or matters such as excitement, activation, and alertness (Terry et al. 2003). For our purposes, however, we were interested in a relatively stable affective and energetic outcome, thereby precluding relatively short-lived indicators such as excitement or mood as often assessed with the Profile of Mood States instrument (POMS; Andrade and Rodríguez 2018; Zeigler-Hill and Shackelford 2017). Another reason for choosing vigor was its multidimensionality: Shirom's (2011) conceptualization of vigor encompasses the same physical-cognitive-emotional differentiation as our predictors, which enables us to test DISC-R Model assumptions. Finally, vigor has previously been used as an indicator of well-being in general sports samples (e.g., Beedie et al. 2000; Balk et al. 2020) as well as in research on long-distance running (e.g., Roebuck et al. 2018).

\section{Goal and Hypotheses}

The goal of this paper is twofold. First, we want to study the moderating role of resources and recovery in the relation between demands and runners' vigor in a sample of longdistance runners. Second, we want to test the relevance, validity, and generalizability of the matching principle of the DISC-R Model in a sports context. In both these goals our main outcome variables are the three dimensions of vigor as key indicators of long-distance runners' well-being. Studying how balance in demands, resources, and recovery relates to vigor might give us important insights for optimizing longdistance runners' well-being, for example by identifying target areas for interventions. Given the number of people who practice running (Hulteen et al. 2017) such outcomes could be impactful as they allow runners to optimize their energy levels by shifting certain aspects of their training. Four hypotheses are formulated according to our theoretical framework (see also Fig. 1), with each of the first three hypotheses pertaining to a specific vigor outcome:

Hypothesis 1: Higher demands are associated with higher physical vigor (i.e., physical strength) under the condition of higher resources (Hypothesis 1a), under the condition of higher recovery (Hypothesis $1 \mathrm{~b}$ ), and with 
even higher physical strength under condition of both higher resources and recovery (Hypothesis 1c).

Hypothesis 2: Higher demands are associated with higher cognitive vigor (i.e., cognitive liveliness) under the condition of higher resources (Hypothesis 2a), under the condition of higher recovery (Hypothesis 2b), and with even higher cognitive liveliness under condition of both high resources and recovery (Hypothesis $2 \mathrm{c}$ ).

Hypothesis 3: Higher demands are associated with higher emotional vigor (i.e., emotional energy) under the condition of higher resources (Hypothesis 3a), under the condition of higher recovery (Hypothesis 3b), and with even higher emotional energy under condition of both higher resources and recovery (Hypothesis 3c).

Hypothesis 4: The strength of moderating effects is positively associated with their degree of match, such that they rank in the following order from low to high: (1) non-matches, (2) double-matches, and (3) triple-matches.

\section{Methods}

\section{Sampling Procedures and Inclusion Criteria}

Cross-sectional survey data were gathered from runners at the Belfius Brussels Marathon 2016, which offered races at $1 \mathrm{~km}$ (kids, $n=700), 5 \mathrm{~km}(n=2500), 21 \mathrm{~km}(n=7600)$, and $42 \mathrm{~km}$ $(n=1700)$. An online questionnaire was emailed to all who finished their race and had agreed to be contacted for research. Prior to participations, all recipients were informed about the study purpose and data anonymization, conform the ethical principles of the Declaration of Helsinki (World Medical Association 2013) and the American Psychological Association (American Psychological Association 2017). About 12,500 runners finished their race, 3293 of whom filled out our questionnaire (response rate of $26.3 \%$ ).

Of these respondents, we only included runners who: (1) completed the half or full marathon (i.e., long-distance runners); (2) considered running their only or main sport; (3) ran at least three months and trained at least monthly; and (4) were older than 16. Applying these four inclusion criteria resulted in 796 respondents. To warrant the validity of our findings we excluded all respondents with $>10 \%$ missing data, resulting in our final sample $(n=623)$ which was used in all further analyses.

\section{Participant Characteristics}

The final sample consisted of 197 women (31.6\%) and 421 men $(67.6 \%)$, aged 16 to 76 years old $(M=40.0 ; S D=11.2)$. Nearly all participants lived in either Belgium (94.4\%) or the Netherlands (4.2\%). Most participants picked the Dutch version of our questionnaire $(n=588,94.4 \%)$ over the English version $(n=35,5.6 \%)$. Most $(75.5 \%)$ were higher educated (i.e., university or university of applied sciences), with the remainder $(24.5 \%)$ having a primary or secondary school education. The majority $(95.5 \%)$ had a daytime occupation (e.g., study, full-time work, part-time work), with a small proportion of the participants $(4.3 \%)$ being retired or 'unspecified' (e.g., unemployed, retired). These sociodemographic characteristics were comparable to previous large-scale running studies in Western Europe (e.g., Scheerder et al. 2015).

Our sample consisted of 498 (79.9\%) half and 125 (20.1\%) whole marathon runners. Most runners $(82.6 \%)$ trained at least twice a week, with the majority running between $6 \mathrm{k}$ to $10 \mathrm{k}$ (34.2\%) and $11 \mathrm{k}$ to $15 \mathrm{k}(47.8 \%)$ per training session. About $10 \%(11.1 \%)$ had less than a year of running experience and half of the runners had more than five years of running experience $(49.9 \%)$. The majority $(87.6 \%)$ had competed in prior running events.

\section{Measures and Covariates}

\section{Running-Related Demands and Resources}

We used the DISQ-Sport 1.0 NL and UK (Balk et al. 2018a) to measure demands and resources in running. This measure has been psychometrically validated on athletes from a variety of sports and levels, in a study which also included a subset of the data used in the current paper (Balk et al. 2018a). It has since been used in several studies (e.g., Balk et al. 2018b, 2020). All questions were introduced with the general opening "In my running sport...". Demands had four items for each dimension, comprising the physical (e.g., I have to expend a lot of physical effort), cognitive (e.g., I need to display high levels of concentration and precision), and emotional (e.g., I have to deal with people whose problems touch me emotionally) dimension. Resources were measured with three items for each dimension: the physical (e.g., I have the opportunity to take a physical break when things get physically strenuous), cognitive (e.g., I have the opportunity to determine my own training method), and emotional (e.g., I get emotional support from others when an upsetting situation occurs) dimension. All items were answered on a 5-point Likert scale from 1 "never applicable" to 5 "always applicable".

\section{Running-Related Recovery}

In line with prior research (e.g., Eccles and Kazmier 2019; Balk et al. 2019; de Jonge et al. 2018), recovery is measured as detachment (Sonnentag and Fritz 2007). Detachment is defined as “an individual's sense of being away from the work situation" (Etzion et al. 1998, p. 579) and represents how one 
recovers to pre-effort levels by allowing the taxed systems to no longer exert effort. Detachment from running was measured using the DISQ-R Sport 1.2 NL and UK (Balk et al. 2017; de Jonge et al. 2012). The three dimensions, with three items each, were physical (e.g., I physically relax from my sport efforts), cognitive (e.g., I put all thoughts about my sport activities aside), and emotional recovery (e.g., I emotionally distance myself from my sport activities). All items were introduced with "In the week before running in the Brussels Marathon..." and answered on a 5-point Likert scale from 1 "never applicable" to 5 "always applicable".

\section{Runners' Vigor}

We assessed vigor of runners with the Dutch and English version of the Shirom-Melamed Vigor Measure (SMVM; Shirom 2003, 2011) and substituting work-specific elements such as "co-workers and customers" with the more generalized "others". The SMVM contains five items for physical strength (e.g., I feel I have physical strength), three items for cognitive liveliness (e.g., I feel I can think rapidly), and four items for emotional energy (e.g., I feel capable of being sympathetic with others). Items were introduced with "In the week after running in the Brussels Marathon..." and were scored on a 7-point Likert scale rated from 1 "never" to 7 "always".

\section{Demographic Characteristics}

In our analyses we controlled for age (years) and gender $(0=$ male and $1=$ female) based on a similar study (Balk et al. 2017); socio-economic status by level of education (in ascending order from primary school to university) and occupation/study ( $0=$ no, $1=$ yes) based on Shirom (2011); and exercise by average training distance $(\mathrm{km})$ and number of trainings per week. Note that demands differ from these training characteristics, as demands are the subjective of experienced running training, whereas training characteristics are a more objective measurement of actual training loads. This allows us to also partially control for variability in exercise response (Ross et al. 2019).

\section{Reliability and Factorial Validity}

Table 1 shows the relevant reliability scores for our measures. All measures had satisfactory (Hair et al. 2014) internal consistencies (Cronbach's alphas ranging from .71 to .96), except for physical demands (alpha $=.61$ ). The average variance explained (AVE) statistic was above .50 for all constructs except for cognitive resources (.47) and physical demands (.29). The squared correlations with other latent constructs of both these exceptions were still lower than its AVE, indicating that they still measure unique constructs. Physical demands specifically, however, requires cautionary interpretation due to its AVE score and somewhat lower reliability score. To test the factorial structure of our measures, we performed two confirmatory factor analyses with Mplus 8.0 (Muthén and Muthén 1998-2017): one for the independent variables (i.e., demands, resources, recovery, and allowing cross-loading between constructs) across their respective dimensions (i.e., physical, cognitive, and emotional); and one for the dependent variable vigor and its three dimensions. Situation-specific cut-off points for fit indices as suggested by Hair et al. (2014) were used to judge goodness-of-fit in both tests.

For the independent variables the overall Chi-square test was significant $\left(\chi^{2}(369)=1115.73, p<0.001\right)$, which was expected and likely resulted from the large sample size. All other model fit indices indicated a reasonable to good fit of the factor structure $(\mathrm{CFI}=0.93, \mathrm{TLI}=0.92, \mathrm{SRMR}=0.055$, RMSEA $=0.057[0.053 ; 0.061])$. For the dependent variable (i.e., vigor) we allowed three separate intra-dimensional item sets to have correlated error terms. The Chi-square test was significant $(\chi 2(48)=222.72, p<0.001)$, likely for similar reasons as the previous test. Other model fit indices indicated a reasonable to good fit of the factor structure $(\mathrm{CFI}=0.98$, $\mathrm{TLI}=0.97, \mathrm{SRMR}=0.044, \mathrm{RMSEA}=0.076[0.066 ; 0.087]$.

\section{Power Analysis}

We conducted a post-hoc power analysis with $\mathrm{G}^{*}$ power 3.1.9.4 (Faul et al. 2009). Based on similar studies (e.g., Balk et al. 2019, 2018b), we expected a medium effect size $\left(F^{2}=.15\right)$. Power was over 99 in our most complex model (i.e., 27 predictors) in detecting $R^{2}$ deviations from zero.

\section{Statistical Analysis}

Hierarchical regression analyses were conducted with incremental $F$-test procedures (Aiken and West 1991) in SPSS 25 to test our hypotheses. No significant violations of linear regression assumptions were detected. This included multicollinearity; we found both tolerance and VIF values to be well within acceptable ranges (i.e., above 0.1 and below 5 , respectively). In the first step, the tested model included the six control variables. In step 2, main effects of demands, resources, and recovery, were added for each dimension (i.e., physical, cognitive, emotional). In the third step, we included two-way interactions (i.e., demands $\mathrm{x}$ resources, demands $\mathrm{x}$ recovery, and resources $\mathrm{x}$ recovery) for each dimension as functions of grand mean centered variables. Note that our hypotheses do not encompass resources $\mathrm{x}$ recovery interactions, as this is beyond the scope of this study. They were only included as a statistical prerequisite for the predicted threeway interactions. In step 4 , the three-way interactions (demands $\mathrm{x}$ resources $\mathrm{x}$ recovery) for each dimension were included. This stepwise approach is in line with previous DISC$\mathrm{R}$ studies (e.g., de Jonge et al. 2012). To reduce possible multicollinearity issues, all interactions were functions of 
Table 1 Descriptives, zero-order Pearson correlations, and reliability of study variables

\begin{tabular}{|c|c|c|c|c|c|c|c|c|c|c|c|c|c|c|c|c|c|c|c|c|}
\hline & M & SD & 1 & 2 & 3 & 4 & 5 & 6 & 7 & 8 & 9 & 10 & 11 & 12 & 13 & 14 & 15 & 16 & 17 & 18 \\
\hline 1. Age & 39.88 & 11.27 & $(-)$ & & & & & & & & & & & & & & & & & \\
\hline 2. $\operatorname{Sex}^{\mathrm{a}}$ & 0.32 & 0.47 & -.25 & $(-)$ & & & & & & & & & & & & & & & & \\
\hline 3. Occupation ${ }^{\mathrm{b}}$ & 0.96 & 0.20 & .24 & -.06 & $(-)$ & & & & & & & & & & & & & & & \\
\hline 4. Education ${ }^{\mathrm{c}}$ & 4.14 & 1.89 & -.20 & .12 & -.04 & $(-)$ & & & & & & & & & & & & & & \\
\hline 5. Training distance $\mathrm{e}^{\mathrm{e}}$ & 2.75 & 1.85 & .19 & -.25 & .07 & -.18 & $(-)$ & & & & & & & & & & & & & \\
\hline 6. Training frequency ${ }^{\mathrm{f}}$ & 4.40 & 1.00 & .22 & -.15 & .03 & -.27 & .34 & $(-)$ & & & & & & & & & & & & \\
\hline 7. Physical demands & 2.35 & 1.58 & -.10 & -.10 & .01 & -.03 & -.04 & .06 & .62 & & & & & & & & & & & \\
\hline 8. Cognitive demands & 2.20 & 1.85 & .07 & -.16 & -.02 & -.16 & .06 & .08 & .43 & .86 & & & & & & & & & & \\
\hline 9. Emotional demands & 1.38 & 1.59 & .08 & -.02 & .02 & -.11 & .02 & .02 & .28 & .44 & .86 & & & & & & & & & \\
\hline 10. Physical resources & 3.96 & 1.84 & -.07 & .09 & .01 & .15 & -.11 & -.05 & -.04 & -.20 & -.29 & .84 & & & & & & & & \\
\hline 11. Cognitive resources & 4.18 & 1.74 & .03 & -.02 & .03 & .02 & .03 & .10 & -.05 & -.03 & -.22 & .59 & .71 & & & & & & & \\
\hline 12. Emotional resources & 3.14 & 1.26 & -.06 & .23 & .00 & -.01 & .06 & .05 & -.02 & .00 & .13 & .17 & .21 & .92 & & & & & & \\
\hline 13. Physical recovery & 2.40 & 1.05 & .00 & -.12 & .00 & .10 & .00 & -.11 & .09 & .12 & .12 & -.01 & .01 & .03 & .85 & & & & & \\
\hline 14. Cognitive recovery & 2.13 & 1.92 & -.07 & -.08 & .05 & .15 & -.13 & -.16 & .07 & .09 & .14 & -.02 & -.05 & .05 & .64 & .80 & & & & \\
\hline 15. Emotional recovery & 2.12 & 1.01 & -.01 & -.10 & .04 & .12 & -.06 & -.11 & .06 & .09 & .13 & -.03 & -.07 & .00 & .69 & .77 & .88 & & & \\
\hline 16. Physical strength & 5.16 & 1.01 & .03 & .01 & -.04 & -.13 & .25 & .17 & -.04 & -.03 & -.11 & .08 & .12 & .13 & -.15 & -.18 & -.11 & .96 & & \\
\hline 17. Cognitive liveliness & 4.99 & 1.06 & .06 & -.02 & -.07 & -.07 & .18 & .15 & -.05 & .04 & -.05 & .10 & .15 & .20 & .00 & -.05 & -.01 & .68 & .92 & \\
\hline 18. Emotional energy & 5.27 & 1.04 & -.02 & .08 & -.03 & -.04 & .17 & .10 & -.07 & -.04 & -.05 & .15 & .15 & .29 & -.05 & -.09 & -.11 & .53 & .59 & .9 \\
\hline
\end{tabular}

Listwise $N=600$. Cronbach's alphas are on diagonal, Omega coefficients were also calculated and maximum deviation from Cronbach's alpha was .016. All correlations $\geq .08$ are significant at $p<.05$; all correlations $\geq .11$ are significant at $p<.01$

${ }^{\mathrm{a}} 0=$ male and $1=$ female ${ }^{\mathrm{b}} 0=$ no work/study and $1=$ has work/study. ${ }^{\mathrm{c}}$ Ranging from 1 ("primary school") to 5 ("university"). ${ }^{\mathrm{e}}$ Per training, from 1 $(0-5 \mathrm{~km})$ with equidistant steps to 6 (more than $26 \mathrm{~km}$ ). ${ }^{\mathrm{f}}$ Ranging from 1 ("Some times per year") to 6 ("more than 4 times a week"), on average people ran at least twice a week

multiplied grand mean centered variables (de Jonge et al. 2012). In accordance with previous studies on the DISC-R Model and the model's specific predictions, two-way and three-way interactions were only tested for matching predictors (e.g., emotional demands $\mathrm{x}$ emotional resources).

Following Roisman et al. (2012), interaction slopes (i.e., +1 $S D$ and $-1 S D$ ) of significant interaction terms were tested and illustrated with regions of significance. The darkened background denotes a region across the values of the predictor where the two slopes of the moderator differ significantly (i.e., $p<.05)$. The area encompassing the moderator lines denotes the upper and lower bounds within which these lines (i.e.,) are significant (i.e., $p<.05$ ).

Lastly, we tested whether matching interactions provided stronger effects than non-matching interactions in several steps using R 3.6.1 (R Core Team 2019). First, we took standardized beta coefficients of all matching (i.e., double and triple) and non-matching two-way interactions. Second, we computed the squared root of these coefficients to make them positive, as we were interested in strength of coefficients and not direction, and then created Z-scores per outcome to assure uniform and comparable data. Third, we defined degree of match for each moderation as either non-match, double match or triple match. Finally, we ran a Kruskal-Wallis test to compare coefficient strength between non-matches, double matches, and triple matches, with Holm correction in posthoc individual tests (Aickin and Gensler 1996).

\section{Results}

Descriptive statistics and zero-order Pearson correlations of study variables can be found in Table 1 . Noteworthy findings were detected with regard to the control variables: higher training distance was associated with higher scores on all dimensions of vigor, having a job or study was associated with lower cognitive liveliness, and being female was associated with higher levels of physical strength. Neither the best fitting steps for any of our models nor the associated number of significant interactions for vigor outcomes were affected by use of control variables.

With regard to our main variables (see Table 1), scores on emotional demands were relatively low compared to other demands and all scores on recovery were noticeably lower than scores on resources. Within each key construct (i.e., demands, resources, recovery, and vigor), we found significant associations for each of its dimensions (e.g., the cognitive, physical, and emotional aspects of demands were all associated). Only one out of nine relations between demands and vigor was significant; a negative 
relation between emotional demands and physical strength. Resources revealed more associations with vigor, with nine out of nine relations being significantly positive. Lastly, recovery showed six out of nine possible relations with vigor to be significant, all revealing positive relations.

Table 2 Results of the hierarchical multiple regression analyses predicting vigor from running-related demands, resources, and recovery (DISC-R Model test)

\begin{tabular}{|c|c|c|c|c|c|c|}
\hline \multirow[t]{3}{*}{ Predictor } & \multicolumn{6}{|l|}{ Vigor } \\
\hline & \multicolumn{2}{|c|}{ Physical strength ${ }^{\mathrm{a}}$} & \multicolumn{2}{|c|}{ Cognitive liveliness $^{\mathrm{a}}$} & \multicolumn{2}{|c|}{ Emotional energy ${ }^{\mathrm{b}}$} \\
\hline & $\Delta R^{2}$ & $b^{\mathrm{c}}$ & $\Delta R^{2}$ & $b^{\mathrm{c}}$ & $\Delta R^{2}$ & $b^{\mathrm{c}}$ \\
\hline Step 1: Control variables & $.09 * * *$ & & $.05 * * *$ & & $.05 * *$ & \\
\hline Age & & .00 & & .00 & & .00 \\
\hline Sex & & $.10^{*}$ & & .00 & & .09 \\
\hline Occupation & & -.04 & & $-.06^{*}$ & & -.02 \\
\hline Education & & -.09 & & -.02 & & -.02 \\
\hline Training distance & & $.26 * * *$ & & $.16^{* *}$ & & $.20 * * *$ \\
\hline Trainings per week & & .06 & & .09 & & .05 \\
\hline Step 2: Main effects & $.05 * * *$ & & $.06 * * *$ & & $.09 * *$ & \\
\hline Physical demands & & .01 & & -.05 & & -.05 \\
\hline Physical resources & & .05 & & .07 & & $.14^{*}$ \\
\hline Physical recovery & & $-.13 *$ & & .00 & & .02 \\
\hline Cognitive demands & & .03 & & .09 & & .02 \\
\hline Cognitive resources & & .06 & & .07 & & .00 \\
\hline Cognitive recovery & & $-.16^{*}$ & & -.05 & & .00 \\
\hline Emotional demands & & $-.19 *$ & & -.08 & & -.03 \\
\hline Emotional resources & & $.09 *$ & & $.16^{* * * *}$ & & $.25 * * *$ \\
\hline Emotional recovery & & $.14^{*}$ & & .05 & & -.12 \\
\hline Step 3: Two-way interactions & .02 & & $.03^{*}$ & & $.03^{*}$ & \\
\hline \multicolumn{7}{|l|}{ Physical } \\
\hline Demands x Resources & & & & -.02 & & -.06 \\
\hline Demands x Recovery & & & & $.20 *$ & & .03 \\
\hline Recovery x Resources & & & & .05 & & .09 \\
\hline \multicolumn{7}{|l|}{ Cognitive } \\
\hline Demands x Resources & & & & .11 & & .04 \\
\hline Demands x Recovery & & & & .04 & & .09 \\
\hline Recovery x Resources & & & & -.06 & & $-.14 *$ \\
\hline \multicolumn{7}{|l|}{ Emotional } \\
\hline Demands x Resources & & & & .00 & & $.17^{*}$ \\
\hline Demands x Recovery & & & & $-.23 *$ & & $-.25 * *$ \\
\hline Recovery x Resources & & & & .06 & & $.07 *$ \\
\hline $\begin{array}{l}\text { Step 4: Three-way interactions } \\
\text { Physical }\end{array}$ & .00 & & .00 & & .00 & \\
\hline \multicolumn{7}{|c|}{ Demands x Resources x Recovery } \\
\hline \multicolumn{7}{|l|}{ Cognitive } \\
\hline \multicolumn{7}{|c|}{ Demands x Resources x Recovery } \\
\hline \multicolumn{7}{|l|}{ Emotional } \\
\hline \multicolumn{7}{|l|}{ Demands x Resources x Recovery } \\
\hline Best-fitting model & $\begin{array}{l}R^{2}=.1 \\
\quad(\mathrm{Mo}\end{array}$ & $\begin{array}{l}5)=6.40 p<.001 \\
\text { justed } R^{2}=.12\end{array}$ & $\begin{array}{l}R^{2}=.1 \\
\quad(\mathrm{Mo}\end{array}$ & $\begin{array}{l}6)=3.89 p<.05 \\
\text { usted } R^{2}=.10\end{array}$ & $\begin{array}{l}R^{2}=. \\
\quad(\mathrm{M}\end{array}$ & $\begin{array}{l}5)=5.02 p<.05 \\
\text { usted } R^{2}=.14\end{array}$ \\
\hline
\end{tabular}


Following our approach as outlined in 2.6, we tested our hypotheses with regression analyses and visualized the outcomes. These outcomes are summarized per dimension of vigor in Table 2 and illustrated in Figs. 2, 3, 4 and 5. For each outcome, the Durbin-Watson statistic for the selected step lay within the accepted range of 1.5 to 2.5 .

\section{Predictors of Physical Strength}

No moderating effects were found for physical strength, as step 2 (i.e., main effects only) best fitted the data $\left(R_{\text {Adj }}^{2}=.12\right)$. In terms of main effects, we found that emotional resources $(b=.09, p=.012)$ and emotional recovery ( $b=.14, p=.033$ ) were significantly positively associated with physical strength. Conversely, emotional demands $(b=$ $-.19, p=.015)$, physical recovery $(b=-.13, p=.017)$, and cognitive recovery $(b=-.16, p=.027)$ were significantly negatively related to physical strength.

\section{Predictors of Cognitive Liveliness}

For cognitive liveliness, step 3 (i.e., main effects and two-way interactions) proved the best model fit $\left(R^{2}\right.$ Adj $\left.=.10\right)$ and revealed two interactions. The first interaction, in line with hypothesis $2 b$, showed that the relation between physical demands and cognitive liveliness was moderated by physical recovery $(b=.20, p=.011)$, with high recovery seemingly resulting in a predicted positive slope compared to low recovery. However, neither of these slopes were significant. The second interaction showed that the relation between emotional demands and cognitive liveliness was moderated by emotional recovery $(b=-.23, p=.011$; see Fig. 2). The direction of this strengthening moderation was in the opposite direction of hypothesis $2 \mathrm{~b}$ : when faced with high emotional demands, having higher scores on emotional recovery related to lower rather than higher cognitive

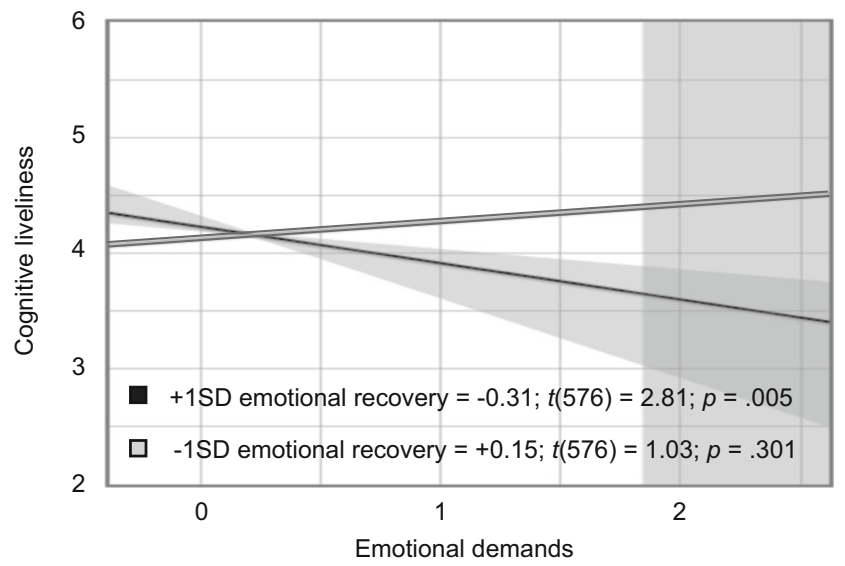

Fig. 2 Emotional demands and emotional recovery interaction on cognitive liveliness

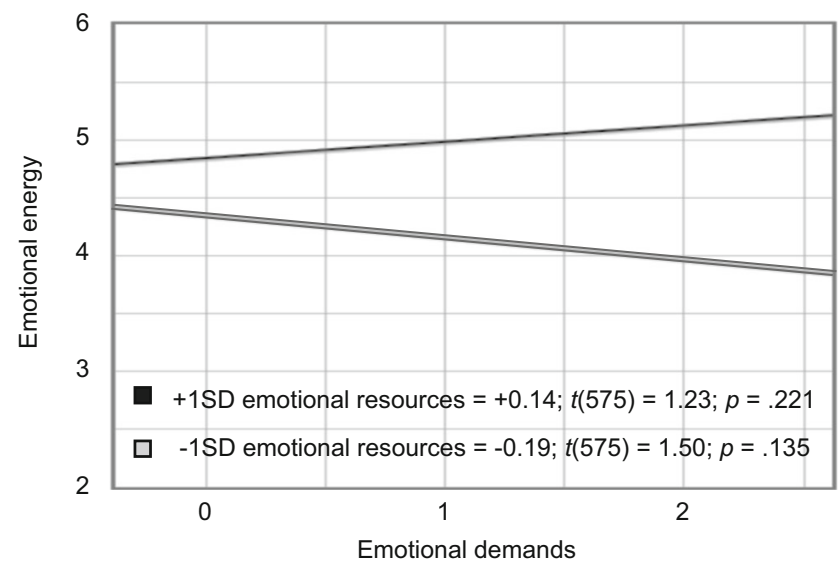

Fig. 3 Emotional demands and emotional resources interaction on emotional energy

liveliness. The associated slope was significant $(p=.005)$, although the slope for lower scores on emotional recovery was not $(p=.301)$. We found one main effect; emotional resources was positively related to cognitive liveliness $(b=.16, p<.001)$.

\section{Predictors of Emotional Energy}

Regarding emotional energy $\left(R_{\text {Adj }}^{2}=.14\right)$, step 3 with main effects and two-way interactions provided the best fit and unveiled two interactions. The first interaction $(b=.17$, $p=.049$, see Fig. 3) showed that the relation between emotional demands and emotional energy was moderated by emotional resources. Slopes appeared in line with hypothesis $3 \mathrm{a}$, as the relation between demands and vigor seemed positive when faced with high resources and negative when faced with low resources. However, further testing showed neither respective slope was significant ( $p=.221 ; p=.135$ ). Our second interaction also occurred on the relation between emotional

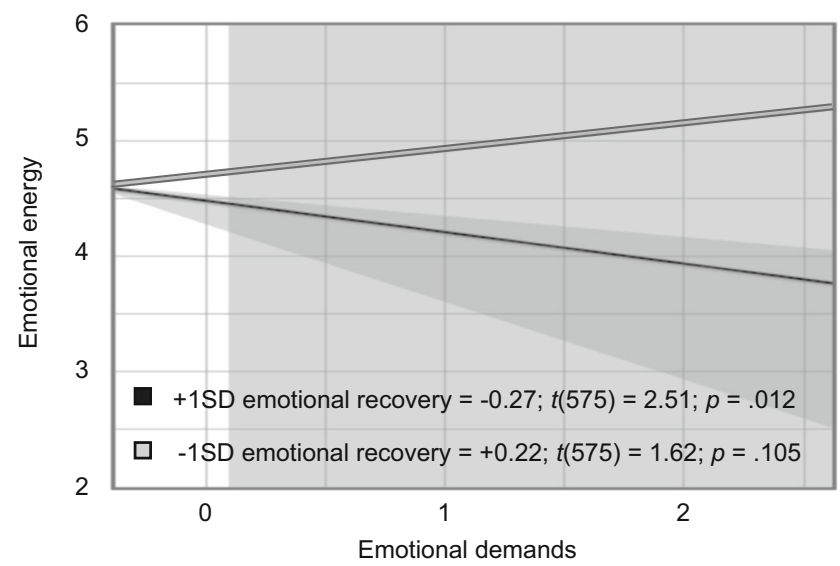

Fig. 4 Emotional demands and emotional recovery interaction on emotional energy 


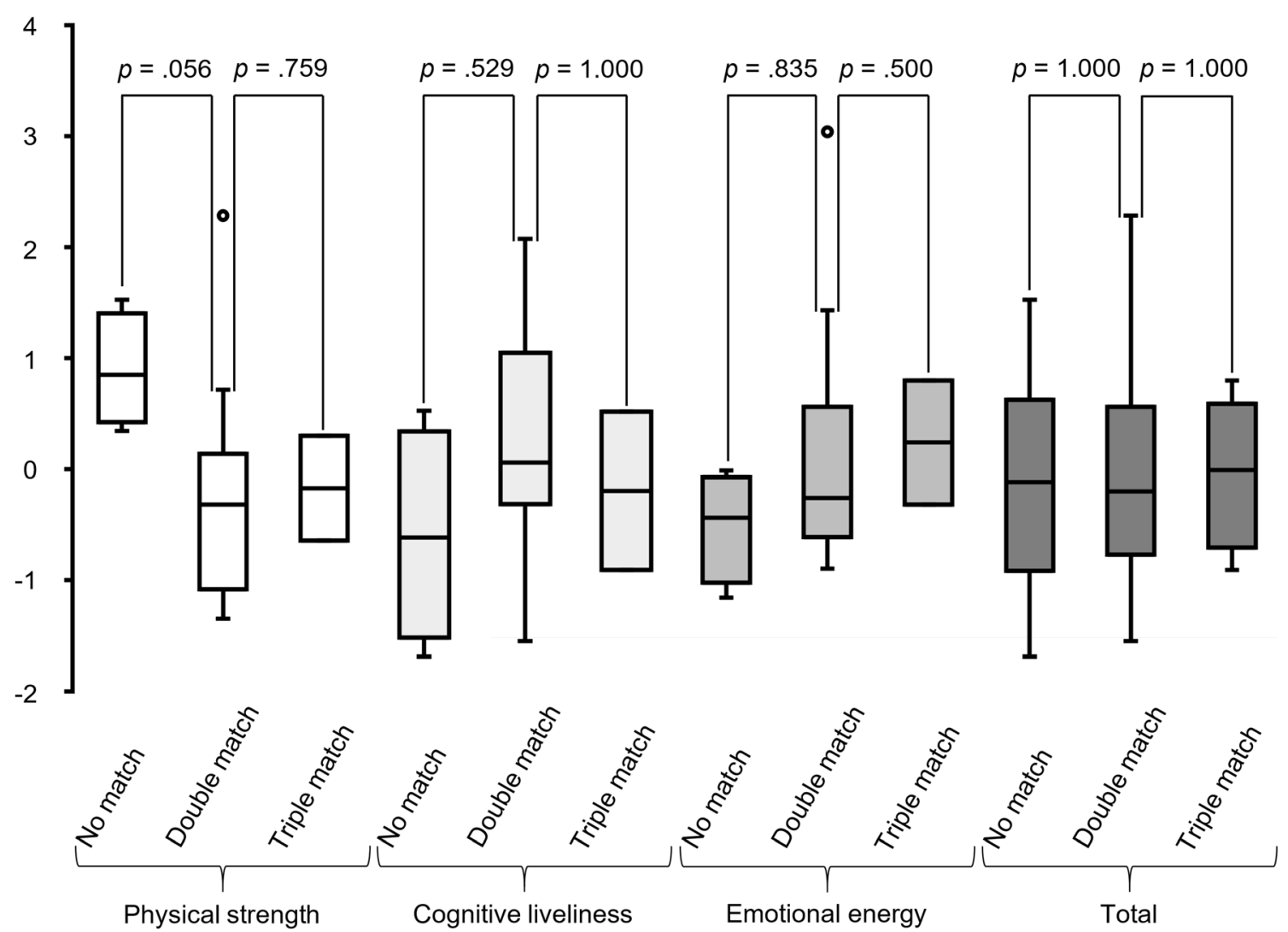

Fig. 5 Boxplot of standardized coefficients strength in non-matching interaction across vigor outcomes

demands and emotional energy, revealing emotional recovery as a strengthening moderator ( $b=-.25, p=.005$, see Fig. 4), albeit in the opposite direction of hypothesis $3 \mathrm{c}$. It showed that, under condition of high demands, emotional recovery was significantly negatively associated with emotional energy rather than positively $(p=.012)$, whereas the slope for lower scores on emotional recovery was not significant $(p=.105)$. Lastly, we found positive main effects for emotional resources $(b=.25, p<.001)$ and physical resources $(b=.14, p=.033)$ on emotional energy.

\section{Testing the Matching Principle}

Our Kruskal-Wallis test revealed that average coefficient strength between non-matches $(M=0.116, n=12)$, double matches $(M=-0.100, n=36)$, and triple matches $(\mathrm{M}=$ $0.371, n=6)$ did not differ significantly $(H(2)=0.002$, $p=.999$ ). In a post-hoc and exploratory approach (i.e., not part of our original hypotheses), we also tested intergroup differences per individual vigor outcome and in total (see Fig. 5). We found no significant results in any of these comparisons. Please note that $p$-values of 1.000 occured due to adjustment for multiple testing using the Holm method (cf., Bonferroni; Aickin and Gensler 1996).

\section{Discussion}

This cross-sectional survey study had two goals: (1) to determine to what degree running-related resources and runningrelated recovery were beneficial to recreational long-distance runners in moderating the relation between running-related demands and vigor, and (2) to establish whether the type of alignment, or 'match', of these constructs on the same dimension (i.e., physical, cognitive, or emotional) related to stronger moderation effects. For both goals we made predictions based on the Demand-Induced Strain Compensation Recovery (DISC-R) Model (de Jonge et al. 2012).

Regarding the first goal, we found evidence for hypotheses $2 \mathrm{~b}, 3 \mathrm{a}$, and $3 \mathrm{~b}$, implying that several dimensions of recovery and resources do indeed moderate the nature of the demandsvigor relation in running. For example, runners facing high physical demands reported higher cognitive liveliness when they had high physical recovery. However, counter to our expectations, runners facing high emotional demands had lower scores on cognitive liveliness and emotional vigor in case they scored high on emotional recovery (i.e., detaching from the emotional aspects of running). No evidence was found for hypotheses 1a, 1b, 1c, 2a, 2c, and 3c. Concerning the second goal, reflected by hypothesis 4 , we found no evidence that resources or recovery moderate the relation 
between demands and vigor more (or less) effectively if those variables matched on the same dimension. In other words: we found no evidence for the match principle affecting the proposed relations in runners.

Overall, although we found but modest evidence for the proposed mechanisms, our findings do confirm that resources or recovery are important for runners' well-being, and that under specific circumstances they play a role in determining the relation between demands and vigor in long-distance running.

\section{Theoretical Implications}

\section{General Implications}

Overall, four out of 27 (15\%) of the predicted matching moderations were found. The associated effect sizes may be considered rather modest, though less so in comparison to similar research (e.g., Balk et al. 2018b). This also does not negate their theoretical importance, as the size of any moderating effect is attenuated by measurement error (i.e., when crossproduct terms are created by multiplying variables in regression analysis; Aiken and West 1991). The average explained variance across all vigor dimensions using the DISC-R Model's predicted moderations was $12 \%$ after correcting for the extra added variables. This number compares favorably to other studies utilizing the DISC-R Model in sport (e.g., Balk et al. 2018b;2019). One could therefor argue that the significant moderating effects we did find portray the usefulness of the DISC-R Model in running, even if only in a somewhat limited fashion. Our results also highlight the usefulness of considering resources and recovery as moderators of the demands-vigor relation.

The fact that we found fewer effects than predicted may originate from the very specific predictions of the DISC-R Model (i.e., matching moderations only). Combined with a hypothesized link between running-specific predictors and a life-wide, as opposed to sport-specific outcome, this may partially explain the modest findings. Although sport participation and well-being are clearly linked (e.g., Nezlek et al. 2018), sport-specific predictors likely relate stronger to sport-specific outcomes (e.g., Sport Mental Health Continuum; Foster and Chow 2018) than to broader, lifewide outcomes. Beyond that, three out of four moderations in the DISC-R Model are concerned with the emotional dimension, which highlights the importance of emotional predictors in long-distance running. In our study, emotional predictors are more influential for well-being outcomes (i.e., vigor) than physical ones. Being capable of explaining cognitive and emotional vigor may be useful in crafting sports to optimize sports participation, as such experiences are highly indicative of adherence to the sport (Stenseng et al. 2015). Our results also show that, in determining cognitive liveliness and emotional energy, how runners deal with their emotional demands is more important than how often or how far they run. This importance of emotional facets in sports for well-being aligns with several other studies (e.g., Balk et al. 2020, 2018b). This is in line with self-regulation theory (e.g., Balk and Englert 2020). The self-regulation of runners in managing emotional demands particularly with emotional resources and recovery seems key. Interestingly, the relation might also be reverse, as a recent study showed that more physical active people may be better at regulating negative emotions (Ligeza et al. 2019). Although we did control for training frequency and distance, this poses the interesting possibility that those with more running experience possessed better efficacy in regulating emotions. Especially in light of the general tendency of literature on sports to focus on physical aspects of predictors and outcomes in sport, these outcomes show that psychological (in our study mostly emotional) aspects of running may deserve further attention.

Finally, although not part of any hypothesis, it is interesting to note that only one out of nine $(11 \%)$ of demands main effects was significant. In other words, demands by themselves seem neither necessarily negative nor positive in relation to vigor. Strength and valence of relations appears to be better predicted by other factors, such as by moderation of resources and recovery. On another note, we framed our narrative around the assumption that resources and recovery moderate the relation between demands and vigor, yet the reverse (i.e., demands moderating the relation between resources/recovery and vigor) might be equally valid. Following this reasoning, one could potentially recommend increasing demands in some situations to prevent 'undertraining' (c.f., Gabbett et al. 2016). Generally, demands are likely to be the action for which resources/recovery are used as a reaction, but the reverse remains an equally interesting perspective. In the following sections we will discuss the specific outcomes on each of the four hypotheses in more detail.

\section{Predictors of Physical Strength}

We found no evidence for the moderations related to physical strength as proposed in hypothesis 1 . This finding conflicts with a study by Balk et al. (2020) on a sample of elite athletes stemming from a variety of sports, where the researchers found that physical resources indeed moderated the relation between physical demands and physical strength. The construct of physical demands is well suited when measuring across a variety of sports (Balk et al. 2018a), but perhaps faces difficulties when measuring matters like such as lifting heavy objects or taking uncomfortable postures in a sample of recreational runners. Measuring this construct without accounting for the specific sport may raise difficulties. Perhaps a relatively one-dimensional sport, such as running, is captured 
less adequately by our instruments compare to composite samples of various athletes or athletes from more dynamic activities, such as wrestling or rugby. Measuring demands in running may hence require a more bespoke approach, focussing more on the specific aspects that runners generally perceive as demanding.

Beyond the lack of moderations for physical strength, we did find multiple main effects which appeared to be in line with the idea of match. Specifically, all emotional dimensions of demands, resources, and recovery appeared to resemble these effects, with higher emotional demands being associated with lower physical strength and higher emotional resources and recovery both being associated with higher physical strength. Furthermore, physical and cognitive recovery were also associated with physical strength, although in a negative fashion rather than the expected positive one. Although these results fall beyond our original theoretical scope concerning moderations, they may indicate that whether runners feel physically strong depends on an interplay between their demands, resources, and recovery (de Jonge et al. 2018).

\section{Predictors of Cognitive Liveliness}

We found partial support for hypothesis 2: two moderations provided some support for hypothesis $2 \mathrm{~b}$ and no support was found for hypothesis $2 \mathrm{a}$ and $2 \mathrm{c}$. The first moderation shows that the relation between physical demands and cognitive liveliness was significantly negative when runners reported low physical recovery, but no such relation existed when they scored higher on physical recovery. To put it differently, physically recovering from running appeared to provide a buffering effect against the negative effects of physical demands on cognitive liveliness. Apparently, physical efforts may dampen cognitive liveliness if recovery is low, although existing research failed to establish such a moderation when testing cognitive recovery state (Balk et al. 2017). The second moderation indicated that higher emotional recovery was associated with lower cognitive liveliness in case of high emotional demands. This was opposite to our expectations, as we hypothesized more emotional recovery to relate positively to cognitive liveliness in case of high emotional demands.

\section{Predictors of Emotional Energy}

Concerning emotional energy, we found evidence for hypotheses $3 a$ and $3 b$ (see Figs. 3 and 4) with two moderating effects. The first moderation shows that emotional resources moderated the relation between emotional demands and emotional vigor (hypothesis 3a). It seems to be a buffering effect, but neither slope was significant which prevents any definitive conclusions.

The second moderation found (hypothesis $3 \mathrm{~b}$ ) functions similar to the one found on cognitive liveliness (hypothesis 2b) in the previous section. It shows that under condition of high emotional demands, emotional energy will be lower if one scores high on emotional recovery. This direction is opposite to expected, showing that lower rather than higher scores on emotional recovery appear to buffer against the detrimental effects of emotional demands. These emotional demands-recovery moderations, occurring on both cognitive liveliness and emotional energy, are the opposite of patterns found in previous studies on positive affect in dance students (Balk et al. 2018b) and on recovery state in elite athletes from a variety of sport backgrounds (Balk et al. 2017). One likely explanation for this is the temporal aspect of our constructs; we asked runners to estimate recovery in the week prior to a running event and vigor in the week after. It is likely that runners were not cognitively and emotionally recovered (i.e., detached) from their sport during a week in which they prepared for their (half) marathon event. Alternatively, we asked whether people were detaching from all emotions, rather than from only negative emotions as is also sometimes considered in literature (e.g., Balk et al. 2017). We may also speculate that those who score high on emotional detachment do so as a result of using suppression as their emotion regulation of choice, which has been known to relate to a construct called negative affect (Molina et al. 2018). This could pose an interesting line of research for future studies. Yet another explanation may be that those who felt emotionally disconnected did so as a result of feeling less vigorous, as our cross-sectional study cannot determine which variable fired first.

If we look for similar physical mechanisms, we find that in other endurance sports active recovery may be better than detaching completely (Kumstát et al. 2019). The role of detachment in work contexts may also prove useful in understanding our findings; a study of work detachment on mental health in Japanese workers showed curvilinear reverse U-shape effects (Shimazu et al. 2016), reinforcing the idea that staying involved to a certain degree is functional. Perhaps, both the physical mechanism and the pattern found in Japanese workers translate to cognitive liveliness and emotional energy. Following this line of reasoning, partial detachment would be more optimal than maximal detachment. To investigate this, we performed posthoc tests for quadratic and cubic effects, yet these were generally unable to explain more variance. The quadratic effects we did find (e.g., emotional detachment on physical strength) occurred in isolated and not particularly sensible fashions. Adhering to linear patterns, our results resemble also a study on workers and creativity where a similar moderation with detachment was found (Niks et al. 2016). Their reasoning is that complete detachment may not be beneficial to creativity outcomes, as creativity is partially fostered by sustained activation. Similarly, too much detachment in runners may be associated with lower levels of well-being. Note that we are not advocating being 
overly mentally obsessive about upcoming sport events, as too much of this exertion may lead to mental fatigue which decreases running performance (Smith et al. 2015). Instead, we solely illustrate that high mental detachment combined with high demands seems to relate to suboptimal vigor.

\section{Match Principle}

We found no evidence for moderations being stronger based on their degree of match (hypothesis 4, see Fig. 5). This implies that the strength of resources and recovery in moderating the demands-vigor relation does not seems to depend on their respective dimensions. This conflicts with a different study where the significance of such moderations was reported to relate to the degree of match in a sample of elite athletes, although no statistical test was used (Balk et al. 2020). Notwithstanding our findings, it should be noted that the match principle has a strong theoretical basis and has also been confirmed in other contexts such as work or study (c.f., de Jonge et al. 2019). However, perhaps this principle is not as consistent across all contexts, especially when considering less pervasive life domains. For elite athletes, for example, their sport can be counted as work (Balk 2018) and aspects thereof likely strongly influences their well-being. In contrast, the recreational athletes of our sample likely experience their sport more as a hobby, with their work, private life, and other hobbies likely posing larger influences on their general well-being. This contrast may have confounded our results, as we measured with a broad outcome (i.e., vigor). It is also possible that sport-general, as opposed to running-specific, measures did not adequately measure the match principle. For now, we cannot conclude that match is related to the moderation strength of resources and recovery in the context of recreational long-distance running.

\section{Practical Implications}

Based on this paper's findings, we have suggestions for those who organize and practice running. First, optimizing and regulating vigor in runners is a complicated matter and requires accounting for cognitive and emotional aspects. Particularly emotional aspects of coping strategies, such as emotional support from running mates or coaches, seem to play a very important role in predicting vigor of runners. Emotional support appears effective, irrespective of levels of demands, and was the most consistent effect boosting vigor we found. Coaches and trainers in particular may take note of this and may try to facilitate emotional resources, for example by supporting runners or encouraging social interaction among runners. However, as specific preferences in social matters are rarely uniform, this likely requires a bespoke approach. For instance, not all people are keen on seeking and asking for emotional support. So, interventions should not only evolve around the availability of emotional resources, but also around ways to stimulate runners to evoke empathy and companionship from their social network (van de Ven et al. 2013). Second, when faced with higher mental (i.e., cognitive and emotional) efforts one may try to detach from those efforts. Our study shows that in some of those scenarios (i.e., before a race) mentally disconnecting too much might be detrimental to vigor. Hence runners should be weary of overly mentally detaching, particularly around competition time.

\section{Research Strengths and Limitations and Future Research Directions}

An obvious strength of our study is the relatively large and representative sample with sufficient power. Important limitations include the cross-sectional nature of our study, which precludes causal reasoning to a large extent. Yet, crosssectional research designs are still necessary and pivotal for matters such as replication research (Spector 2019). Another possible limitation is overestimation of relations between variables due to common method variance arising from the use of self-report data. Nevertheless, research studies have shown that this influence is not as high as commonly believed (e.g., Lance et al. 2010).

The DISC-R Model presents a unique and broad perspective, as it not only includes demands but also encompasses the utilization of resources and recovery strategies. Moreover, it distinguishes physical, cognitive, and emotional aspects, enabling a more refined approach than accounting for either general demands or for only looking at physical aspects. However, it does not account for some other matters which may be required to fully understand runners' well-being. We provide several suggestions for improvement for future likeminded studies. First, in repeating study designs such as ours it is recommended to include more contextual information (e.g., related to perception of competition events). Second, personality of runners likely plays a role in how people perceive and experience various aspects of their sport. We therefore recommend also including concepts pertaining to personality characteristics such as harmonious and obsessive passion (de Jonge et al. 2018; Stenseng et al. 2015), mental toughness (Mann and Narula 2017), or mindfulness and acceptance (Bernier et al. 2009). Third and final, sport-specific aspects (e.g., demands) likely influence sport-specific outcomes more strongly than they influence general life outcomes, hence we recommended usage of sport-specific outcomes (e.g., sport engagement and performance) to either replace or supplement general outcomes.

\section{Conclusion}

To conclude, this study provides insight into the role of running-related resources and recovery, and how they 
moderate the relation between running-related demands and long-distance runners' vigor. Furthermore, we did not find evidence supporting that matching running-related predictors on identical dimensions (i.e., physical, cognitive, and emotional) relates to higher coping effectiveness of resources and recovery. Emotional aspects of running were found to be most important, as emotional resources and emotional recovery made up the majority of the effects that were found. All in all, this study highlights the utility of considering matching coping strategies, in particular emotional resources and recovery, in the relation between demands and vigor of recreational long-distance runners.

Acknowledgments This work was partially supported by The Netherlands Organisation for Health Research and Development (ZonMW) under grant number 536001003. We would like to thank Mark Janssen, Ruben Walravens, and Ruth Voskuil for assisting in data collection, and all participants for their input in this study. A subset of the data used for this study has been used in a previously published article. No potential conflict of interest was reported by the authors.

Author Contributions Jan de Jonge and Steven Vos contributed to the study conception and design. Material preparation, data collection and analysis were performed by Luuk van Iperen, Jan de Jonge, and Steven Vos. The first draft of the manuscript was written by Luuk van Iperen and all authors commented on previous versions of the manuscript. All authors read and approved the final manuscript.

\section{Compliance with Ethical Standards}

Conflict of Interest All authors declare that there is no potential conflict of interest, competing financial interest, or personal relationships that influenced the work reported in this paper.

Financial Disclosure Luuk P. van Iperen has no financial disclosures. Jan de Jonge has no financial disclosures. Josette M.P. Gevers has no financial disclosures. Steven B. Vos has no financial disclosures.

Open Access This article is licensed under a Creative Commons Attribution 4.0 International License, which permits use, sharing, adaptation, distribution and reproduction in any medium or format, as long as you give appropriate credit to the original author(s) and the source, provide a link to the Creative Commons licence, and indicate if changes were made. The images or other third party material in this article are included in the article's Creative Commons licence, unless indicated otherwise in a credit line to the material. If material is not included in the article's Creative Commons licence and your intended use is not permitted by statutory regulation or exceeds the permitted use, you will need to obtain permission directly from the copyright holder. To view a copy of this licence, visit http://creativecommons.org/licenses/by/4.0/.

\section{References}

Aickin, M., \& Gensler, H. (1996). Adjusting for multiple testing when reporting research results: The Bonferroni vs holm methods. American Journal of Public Health, 86(5), 726-728. https://doi. org/10.2105/ajph.86.5.726.
Aiken, L. S., \& West, S. G. (1991). Multiple regression: Testing and interpreting interactions. Newbury Park: Sage.

American Psychological Association (2017). Ethical principles of psychologists and code of conduct (2002, Amended June 1, 2010 and January 1, 2017) [PDF file]. Retrieved from https://www.apa.org/ ethics/code/. Accessed 29 June 2020.

Andrade, E., \& Rodríguez, D. (2018). Factor structure of mood over time frames and circumstances of measurement: Two studies on the profile of mood states questionnaire. PLoS One, 13(10), e0205892. https://doi.org/10.1371/journal.pone.0205892.

Balk, Y. A. (2018). Faster, higher, stronger: Demands, resources, and recovery as determinants of elite athletes' well-being. Eindhoven University of Technology, Eindhoven, The Netherlands: Doctoral dissertation Retrieved from https://pure.tue.nl/ws/portalfiles/portal/ 110349514/20181008_CO_Yannick_Balk_thesis_amended compressed_pdf. Accessed $2 \overline{9}$ June 2020.

Balk, Y. A., \& Englert, C. (2020). Recovery self-regulation in sport: Theory, research, and practice. International Journal of Sports Science \& Coaching, 15(2), 273-281. https://doi.org/10.1177/ 1747954119897528.

Balk, Y. A., de Jonge, J., Oerlemans, W. G. M., \& Geurts, S. A. E. (2017). Testing the triple-match principle among Dutch elite athletes: A day-level study on sport demands, detachment and recovery. Psychology of Sport and Exercise, 33, 7-17. https://doi.org/10. 1016/j.psychsport.2017.07.006.

Balk, Y. A., de Jonge, J., Oerlemans, W. G. M., Geurts, S. A. E., Fletcher, D., \& Dormann, C. (2018a). Balancing demands and resources in sport: Adaptation and validation of the demand-induced strain compensation questionnaire for use in sport. Journal of Sports Science and Medicine, 17(2), 237-244.

Balk, Y. A., de Jonge, J., van Rijn, R., \& Stubbe, J. (2018b). "Leave it all behind": The role of mental demands and mental detachment in relation to dance students' health and well-being. Medical Problems of Performing Artists, 33(4), 258-264. https://doi.org/ 10.21091/mppa.2018.4038.

Balk, Y. A., de Jonge, J., Oerlemans, W. G. M., \& Geurts, S. A. E. (2019). Physical recovery, mental detachment and sleep as predictors of injury and mental energy. Journal of Health Psychology., 24, 1828-1838. https://doi.org/10.1177/1359105317705980.

Balk, Y. A., de Jonge, J., Oerlemans, W. G. M., \& Geurts, S. A. E. (2020). "What a match!": The specific role of resources in the relation between demands and vigour in elite sport. Applied Psychology., 69, 120-147. https://doi.org/10.1111/apps.12188.

Beedie, C. J., Terry, P. C., \& Lane, A. M. (2000). The profile of mood states and athletic performance: Two meta-analyses. Journal of Applied Sport Psychology, 12(1), 49-68.

Bernier, M., Thienot, E., Codron, R., \& Fournier, J. F. (2009). Mindfulness and acceptance approaches in sport performance. Journal of Clinical Sport Psychology, 3(4), 320-333. https://doi. org/10.1123/jcsp.3.4.320.

de Jonge, J., \& Dormann, C. (2006). Stressors, resources, and strain at work: A longitudinal test of the triple-match principle. Journal of Applied Psychology, 91(6), 1359-1374. https://doi.org/10.1037/ 0021-9010.91.5.1359.

de Jonge, J., \& Dormann, C. (2017). Why is my job so stressful? Characteristics, processes, and models of stress at work. In N. Chmiel, F. Fraccaroli, \& M. Sverke (Eds.), An introduction to work and organisational psychology: An international perspective (pp. 80-101). Chichester: Wiley-Blackwell.

de Jonge, J., Spoor, E., Sonnentag, S., Dormann, C., \& van den Tooren, M. (2012). "Take a break?!" off-job recovery, job demands, and job resources as predictors of health, active learning, and creativity. European Journal of Work and Organizational Psychology, 21(3), 321-348. https://doi.org/10.1080/1359432x.2011.576009.

de Jonge, J., van Iperen, L., Gevers, J., \& Vos, S. (2018). "Take a mental break!" study: Role of mental aspects in running-related injuries 
using a randomised controlled trial. BMJ Open Sport \& Exercise Medicine, 4(1), e000427. https://doi.org/10.1136/bmjsem-2018000427.

de Jonge, J., Peeters, M. C. W., \& Taris, T. W. (2019). Feeling vital or fatigued? Relations with demands and resources in a university context. International Journal of Environmental Research and Public Health, 16(16), 2893. https://doi.org/10.3390/ijerph16162893.

Eccles, D. W., \& Kazmier, A. W. (2019). The psychology of rest in athletes: An empirical study and initial model. Psychology of Sport and Exercise, 44, 90-98. https://doi.org/10.1016/j.psychsport.2019. 05.007 .

Etzion, D., Eden, D., \& Lapidot, Y. (1998). Relief from job stressors and burnout: Reserve service as a respite. Journal of Applied Psychology, 83(4), 577-585. https://doi.org/10.1037/0021-9010. 83.4.577.

Evans, M., Rohan, K. J., Howard, A., Ho, S.-Y., Dubbert, P. M., \& Stetson, B. A. (2017). Exercise dimensions and psychological well-being: A community-based exercise study. Journal of Clinical Sport Psychology, 11(2), 107-125. https://doi.org/10. 1123/jcsp.2017-0027.

Faul, F., Erdfelder, E., Buchner, A., \& Lang, A.-G. (2009). Statistical power analyses using $\mathrm{G}^{*}$ power 3.1: Tests for correlation and regression analyses. Behavior Research Methods, 41(4), 1149-1160. https://doi.org/10.3758/brm.41.4.1149.

Foster, B. J., \& Chow, G. M. (2018). Development of the sport mental health continuum - Short form (sport MHC-SF). Journal of Clinical Sport Psychology, 13, 1-27. https://doi.org/10.1123/jcsp.20170057.

Gabbett, T. J., Kennelly, S., Sheehan, J., Hawkins, R., Milsom, J., King, E., Whiteley, R., \& Ekstrand, J. (2016). If overuse injury is a "training load error", should undertraining be viewed the same way? British Journal of Sports Medicine, 50(17), 1017-1018. https:// doi.org/10.1136/bjsports-2016-096308.

Grunseit, A., Richards, J., \& Merom, D. (2017). Running on a high: Parkrun and personal well-being. BMC Public Health, 18(1), 59. https://doi.org/10.1186/s12889-017-4620-1.

Hair, J. F., Black, W. C., Babin, B. J., \& Anderson, R. E. (Eds.). (2014). Multivariate data analysis (7th ed.). Harlow: Pearson Education Limited.

Hausswirth, C., \& Mujika, I. (2013). Recovery for performance in sport. Champaign: Human Kinetics.

Heidari, J., Beckmann, J., Bertollo, M., Brink, M., Kallus, W., Robazza, C., \& Kellmann, M. (2018). Multidimensional monitoring of recovery status and implications for performance. International Journal of Sports Physiology and Performance, 1-24. https://doi.org/10. 1123/ijspp.2017-0669.

Hulteen, R. M., Smith, J. J., Morgan, P. J., Barnett, L. M., Hallal, P. C., Colyvas, K., \& Lubans, D. R. (2017). Global participation in sport and leisure-time physical activities: A systematic review and metaanalysis. Preventive Medicine, 95, 14-25. https://doi.org/10.1016/j. ypmed.2016.11.027.

Kellmann, M., Bertollo, M., Bosquet, L., Brink, M., Coutts, A. J., Duffield, R., Erlacher, D., Halson, S. L., Hecksteden, A., Heidari, J., Kallus, K. W., Meeusen, R., Mujika, I., Robazza, C., Skorski, S., Venter, R., \& Beckmann, J. (2018). Recovery and performance in sport: Consensus statement. International Journal of Sports Physiology and Performance, 13(2), 240-245. https://doi.org/10. 1123/ijspp.2017-0759.

Kumstát, M., Struhár, I., Hlinský, T., \& Thomas, A. (2019). Effects of immediate post-exercise recovery after a high intensity exercise on subsequent cycling performance. Journal of Human Sport and Exercise, 14(2). https://doi.org/10.14198/jhse.2019.142.12.

Lance, C. E., Dawson, B., Birkelbach, D., \& Hoffman, B. J. (2010). Method effects, measurement error, and substantive conclusions. Organizational Research Methods, 13(3), 435-455. https://doi.org/ 10.1177/1094428109352528.
Landolfi, E. (2012). Exercise addiction. Sports Medicine, 43(2), 111119. https://doi.org/10.1007/s40279-012-0013-x.

Lee, D., Pate, R. R., Lavie, C. J., Sui, X., Church, T. S., \& Blair, S. N. (2014). Leisure-time running reduces all-cause and cardiovascular mortality risk. Journal of the American College of Cardiology, 64(5), 472-481. https://doi.org/10.1016/j.jacc.2014.04.058.

Ligeza, T. S., Kałamała, P., Tarnawczyk, O., Maciejczyk, M., \& Wyczesany, M. (2019). Frequent physical exercise is associated with better ability to regulate negative emotions in adult women: The electrophysiological evidence. Mental Health and Physical Activity, 17, 100294. https://doi.org/10.1016/j.mhpa.2019.100294.

Mann, A., \& Narula, B. (2017). Positive psychology in sports: An overview. International Journal of Social Sciences, 6(2), 153. https://doi. org/10.5958/2321-5771.2017.00017.5.

Molina, V. M., Oriol, X., \& Mendoza, M. C. (2018). Emotional regulation and physical recovery in young athletes of individual and collective sport modalities. [Regulación emocional y recuperación física de los jóvenes deportistas en modalidades deportivas individual y colectiva]. RICYDE. Revista Internacional de Ciencias Del Deporte, 14(53), 191-204. https://doi.org/10.5232/ricyde2018. 05301.

Muthén, L. K., \& Muthén, B. O. (1998-2017). Mplus User's Guide (8th ed.). Los Angeles: Muthén \& Muthén.

Nezlek, J. B., Cypryańska, M., Cypryański, P., Chlebosz, K., Jenczylik, K., Sztachańska, J., \& Zalewska, A. M. (2018). Within-person relationships between recreational running and psychological well-being. Journal of Sport and Exercise Psychology, 40(3), 146-152. https://doi.org/10.1123/jsep.2017-0244.

Niks, I. M. W., de Jonge, J., Gevers, J. M. P., \& Houtman, I. L. D. (2016). Divergent effects of detachment from work: A day-level study on employee creativity. European Journal of Work and Organizational Psychology, 26(2), 183-194. https://doi.org/10.1080/1359432x. 2016.1241767.

Pedisic, Z., Shrestha, N., Kovalchik, S., Stamatakis, E., Liangruenrom, N., Grgic, J., et al. (2019). Is running associated with a lower risk of all-cause, cardiovascular and cancer mortality, and is the more the better? A systematic review and meta-analysis. British Journal of Sports Medicine, bjsports-2018-100493. https://doi.org/10.1136/ bjsports-2018-100493.

R Core Team. (2019). R: A language and environment for statistical computing. Vienna, Austria: R Foundation for Statistical Computing Retrieved from https://www.R-project.org/.

Roebuck, G. S., Fitzgerald, P. B., Urquhart, D. M., Ng, S.-K., Cicuttini, F. M., \& Fitzgibbon, B. M. (2018). The psychology of ultra-marathon runners: A systematic review. Psychology of Sport and Exercise, 37, 43-58. https://doi.org/10.1016/j.psychsport.2018.04.004.

Roisman, G. I., Newman, D. A., Fraley, R. C., Haltigan, J. D., Groh, A. M., \& Haydon, K. C. (2012). Distinguishing differential susceptibility from diathesis-stress: Recommendations for evaluating interaction effects. Development and Psychopathology, 24(2), 389-409. https://doi.org/10.1017/s0954579412000065.

Ross, R., Goodpaster, B. H., Koch, L. G., Sarzynski, M. A., Kohrt, W. M., Johannsen, N. M., Skinner, J. S., Castro, A., Irving, B. A., Noland, R. C., Sparks, L. M., Spielmann, G., Day, A. G., Pitsch, W., Hopkins, W. G., \& Bouchard, C. (2019). Precision exercise medicine: Understanding exercise response variability. British Journal of Sports Medicine, 53(18), 1141-1153. https://doi.org/10. 1136/bjsports-2018-100328.

Sato, M., Jordan, J. S., \& Funk, D. C. (2015). Distance running events and life satisfaction: A longitudinal study. Journal of Sport Management, 29(4), 347-361. https://doi.org/10.1123/jsm.20130164.

Scheerder, J., Breedveld, K., \& Borgers, J. (2015). Who is doing a run with the running boom? In J. Scheerder, K. Breedveld, \& J. Borgers (Eds.), Running across Europe (pp. 1-27). Basingstoke: Palgrave Macmillan. https://doi.org/10.1057/9781137446374. 
Shimazu, A., Matsudaira, K., de Jonge, J., Tosaka, N., Watanabe, K., \& Takahashi, M. (2016). Psychological detachment from work during non-work time: Linear or curvilinear relations with mental health and work engagement? Industrial Health, 54(3), 282-292. https:// doi.org/10.2486/indhealth.2015-0097.

Shipway, R., \& Holloway, I. (2013). Health and the running body. International Review for the Sociology of Sport, 51(1), 78-96. https://doi.org/10.1177/1012690213509807.

Shirom, A. (2003). Feeling vigorous at work? The construct of vigor and the study of positive affect in organizations. In Ganster, \& and Perrewe, P.L. (Eds), Research in Organizational Stress and WellBeing (Vol. 3, pp. 135-165). Greenwich: JAI Press.

Shirom, A. (2011). Vigor as a positive affect at work: Conceptualizing vigor, its relations with related constructs, and its antecedents and consequences. Review for General Psychology, 15(1), 50-64. https://doi.org/10.1037/a0021853.

Smith, M. R., Marcora, S. M., \& Coutts, A. J. (2015). Mental fatigue impairs intermittent running performance. Medicine \& Science in Sports \& Exercise, 47(8), 1682-1690. https://doi.org/10.1249/mss. 0000000000000592.

Sonnentag, S., \& Fritz, C. (2007). The recovery experience questionnaire: Development and validation of a measure for assessing recuperation and unwinding from work. Journal of Occupational Health Psychology, 12(3), 204-221. https://doi.org/10.1037/1076-8998. 12.3.204.

Spector, P. E. (2019). Do not cross me: Optimizing the use of crosssectional designs. Journal of Business and Psychology, 34(2), 125-137. https://doi.org/10.1007/s10869-018-09613-8.

Stenseng, F., Forest, J., \& Curran, T. (2015). Positive emotions in recreational sport activities: The role of passion and belongingness. Journal of Happiness Studies, 16(5), 1117-1129. https://doi.org/ 10.1007/s10902-014-9547-y.
Terry, P., Lane, A., \& Fogarty, G. (2003). Construct validity of the profile of mood states - Adolescents for use with adults. Psychology of Sport and Exercise, 4(2), 125-139. https://doi.org/10.1016/s14690292(01)00035-8.

van de Ven, B., van den Tooren, M., \& Vlerick, P. (2013). Emotional job resources and emotional support seeking as moderators of the relation between emotional job demands and emotional exhaustion: A two-wave panel study. Journal of Occupational Health Psychology, 18(1), 1-8. https://doi.org/10.1037/a0030656.

van Poppel, D., Scholten-Peeters, G. G. M., van Middelkoop, M., Koes, B. W., \& Verhagen, A. P. (2018). Risk models for lower extremity injuries among short- and long-distance runners: A prospective cohort study. Musculoskeletal Science and Practice, 36, 48-53. https:// doi.org/10.1016/j.msksp.2018.04.007.

Walter, K., von Haaren, B., Löffler, S., Härtel, S., Jansen, C.-P., Werner, C., Stumpp, J., Bös, K., \& Hey, S. (2013). Acute and medium term effects of a 10-week running intervention on mood state in apprentices. Frontiers in Psychology, 4. https://doi.org/10.3389/fpsyg. 2013.00411.

World Medical Association. (2013). World medical association declaration of Helsinki: Ethical principles for medical research involving human subjects. The Journal of the American Medical Association, 310(20), 2191-2194. https://doi.org/10.1001/jama.2013.281053.

Zeigler-Hill, V., \& Shackelford, T. K. (2017). Encyclopedia of personality and individual differences. Springer International Publishing. https://doi.org/10.1007/978-3-319-28099-8.

Publisher's Note Springer Nature remains neutral with regard to jurisdictional claims in published maps and institutional affiliations. 